\title{
Correction to: Effectiveness of a Short Duration of Neoadjuvant Endocrine Therapy in Patients with HR+ Breast Cancer-An NCDB Analysis (2004-2016)
}

\begin{abstract}
Macy M. Goldbach, BS ${ }^{1} \mathbb{D}$, Laura Burkbauer, BA ${ }^{1}$, Tina Bharani, MD $^{1}$, Austin D. Williams, MD, MSEd ${ }^{3}$, Luke Keele, $\mathrm{PhD}^{2}$, Jami Rothman, $\mathrm{MD}^{1,4}$, Rachel Jankowitz, $\mathrm{MD}^{4}$, and Julia C. Tchou, MD, PhD, FACS ${ }^{1,4}$

${ }^{1}$ Division of Endocrine and Oncologic Surgery, Department of Surgery, Perelman School of Medicine, University of Pennsylvania, Philadelphia, PA; ${ }^{2}$ Division of Epidemiology and Biostatistics, Department of Surgery, Perelman School of Medicine, University of Pennsylvania, Philadelphia, PA; ${ }^{3}$ Department of Surgery, Lankenau Medical Center, Wynnewood, PA; ${ }^{4}$ Rena Rowan Breast Center, Abramson Cancer Center, Perelman School of Medicine, University of Pennsylvania, Philadelphia, PA
\end{abstract}

CORRECTION TO: ANN SURG ONCOL HTTPS://DOI.ORG/10.1245/S10434-021-10287-5

The electronic supplementary material for this article has been updated.
Publisher's Note Springer Nature remains neutral with regard to jurisdictional claims in published maps and institutional affiliations.

The original article can be found online at https://doi.org/10.1245/ s10434-021-10287-5.

(C) Society of Surgical Oncology 2021

Published Online: 15 July 2021

M. M. Goldbach, BS

e-mail: Julia.Tchou@pennmedicine.upenn.edu

J. C. Tchou, MD, PhD, FACS

e-mail: Julia.Tchou@pennmedicine.upenn.edu 